Психология. Журнал Высшей школы экономики,

2018. T. 15. № 1. C. 69-78. DOI: 10.17323/1813-8918-2018-1-69-78

\title{
МОДЕЛЬ СВЯЗЕЙ САМООЦЕНКИ КРЕАТИВНОСТИ И ИНТЕЛЛЕКТА С ТОЛЕРАНТНОСТЬЮ К НЕОПРЕДЕЛЕННОСТИ И КРЕАТИВНОСТЬЮ
}

\author{
Е.М. ПАВЛОВА
}

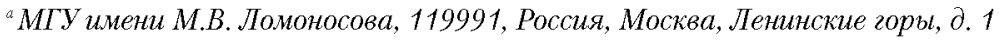

\begin{abstract}
Резюме
Связь самооценок с креативностью (как когнитивной способностью) отражает регулятивную функцию самосознания личности. Самооценки разного вида и разной обобщенности функционируют во взаимодействии с другими составляющими интеллектуально-личностного потенциала человека и выходят на верхние уровни психологической регуляции продуктивности ее деятельности. К связанным с самосознанием личности характеристикам относятся ее толерантность к неопределенности и умение полагаться на интуицию, влияющие на продуктивные выборы и становление новообразований других типов. В данной работе проведено исследование связи креативности (диагностируемой с помощью методики, в которой испытуемый создает творческий продукт, оцениваемый затем экспертами), ее прямой самооценки, интуитивного стиля и толерантности к неопределенности у состоявшихся представителей творческих профессий (писателей, композиторов и режиссеров театра и кино, $\mathrm{n}=53$ ) и контрольной группы студентов-психологов ( $=593)$. С использованием корреляционного анализа показано, что у студентов-психологов самооценка креативности базируется в первую очередь на принятии неопределенности, тогда как состоявшиеся представители творческих профессий строят свою самооценку на основе объективных результатов творческой деятельности. С использованием конфирматорного факторного анализа верифицирована структурная модель связи латентных переменных Креативности, интегральной Самооценки креативности и интеллекта и Принятия неопределенности и риска. Показана положительная связь латентных переменных интегральной Самооценки с Креативностью и Принятием неопределенности и риска, а также отрицательная - Креативности и Принятия неопределенности и риска. Согласно полученным результатам, в отличие от самооценки интеллекта интегральная самооценка связана как с процессами принятия неопределенности, так и с успешностыо творческой деятельности.
\end{abstract}

Ключевые слова: креативность, самооценка креативности, толерантность к неопределенности, готовность к риску, интеллект, интуиция, представители творческих профессий.

Личностная регуляция креативности связывается как с интеллектом и мотивацией, так и с личностными чертами. В отечественной психологии представлены идеи уровневого строения личности и многоуровневости сознания. Верхний уровень личностной саморегуляции - самосознание - включает в себя самооценки, которые отражают когнитивные 
составляющие образа Я, а также ценностное отношение к себе (самоотношение и самопознание). Однако самооценки креативности как образования на уровне самосознания личности в отечественной психологии изучены недостаточно.

При рассмотрении самосознания в качестве ведущего уровня в личностной регуляции действий и решений человека (А.Н. Леонтьев, В.П. Зинченко, В.В. Столин, В.В. Знаков, Т.В. Корнилова и др.) необходима разработка и проверка гипотез о его регулятивной роли. В контексте изучения креативности, необходимо установление связей креативности с ее самооценкой и другими составляющими интеллектуально-личностного потенциала человека, включенными в динамические иерархии психологической регуляции креативных решений.

Разработано множество подходов к изучению креативности; обычно при интерпретации разнообразия эмпирических результатов авторы ссылаются на особенности переменных, шкал и способов оценки креативности. Мы видим решение этой проблемы в комплексном рассмотрении феномена на материале различных методик в совокупности с использованием современных статистических методов, а также через обращение к продуктивному выбору и уровню самосознания личности. Основанием возможности такого комплексного рассмотрения выступает идея единства интеллекта и аффекта (Л.С. Выготский, О.К. Тихомиров), развиваемая в контексте концепции единого интеллектуально-личностного потенциала человека (Корнилова, 2016).
Креативность принято разделять на несколько уровней, в частности, исследователи говорят о «БольшойК» и «малой-к». Первый уровень связывается с уровнем креативности, присущим гениям, достигшим высоких успехов, тогда как «малая-к» связывается с проявлениями креативности в ежедневной жизни. Дополнительно выделяются также «мини-к» (активность, являющаяся оригинальной только для ее автора) и «профессиональная-к», свойственная профессионалам от творческих профессий, не достигшим, однако, легендарных успехов (Kaufman et al., 2010).

Существует некоторый набор характеристик, которые обычно описываются как свойственные успешным в творческой деятельности людям. Среди этих свойств особое место занимают толерантность к неопределенности (ТН) и интуиция. ТН характеризует динамическое отношение к ситуации неопределенности, новизны, двусмысленности, противоречивости и пр. Интуиция означает пути достижения новых результатов в обход осознанной рациональной регуляции мыслительной деятельности.

В отечественной психологии преодоление субъективной неопределенности связывается с выраженностью новообразований как критериев продуктивного или творческого процесса (Корнилова, 2013). В зарубежной психологии также выдвигаются гипотезы о связи ТН и креативности: например, ТН рассматривается разными авторами как помогающая человеку оптимизировать свой креативный потенциал, снимающая чувство тревоги трудных 
ситуаций, помогающая человеку исследовать новые стимулы и т.д. (Любарт и др., 2009; Zenasni et al., 2008).

Проблема выделения отдельных оснований процесса самооценивания существует для отдельных свойств личности, в частности для креативности. Области приложения креативности вошли в фокус внимания психологии не только при обсуждении структуры самооценки креативности, но и в рамках более общей проблемы креативности как общей или специальной способности. Изучение самооценок креативности в разных сферах обычно показывает, что самооценка имеет многоуровневую структуру: например, выделяются факторы «ручной» креативности, научной креативности и эмпатии (Kaufman, Baer, 2005) или креативного стиля жизни, исполнительского мастерства и интеллектуальной креативности (Ivcevic, Mayer, 2009).

То, насколько самооценка отражает объективный уровень развития способности, является дискуссионным вопросом (Jacobs et al., 2012), в том числе и в отношении креативности. При исследовании самооценки креативности в различных сферах зачастую обнаруживается ее низкая или значительная связь с объективными показателями креативности (Reiter-Palmon et al, 2012; Furnham et al., 2011; и др.). Однако нет данных о связях прямых самооценок креативности с отношением к неопределенности.

Целью данной работы стала верификация структурной модели, уста- навливающей связи между предполагаемыми латентными переменными Креативности ${ }^{1}$, интегральной Самооценки креативности и интеллекта и Принятия неопределенности и риска.

\section{Методы}

Уиастники исследования. В исследовании приняли участие в общей сложности 646 человек, 168 мужчин и 478 женщин, в возрасте от 18 до 68 лет $(\mathrm{M}=23.07, \sigma=9.94)$.

Состоявииеся представители твориеских профессий: 53 человека, 42 мужчины и 11 женщин в возрасте от 25 до 68 лет $(\mathrm{M}=45.54, \sigma=10.42)$, все признаны за рубежом и в России, лауреаты соответствующих премий и конкурсов:

1) 21 писатель, 17 мужчин и 4 женщины в возрасте от 30 до 67 лет $(\mathrm{M}=49.57, \sigma=9.21)$;

2) 18 композиторов, 15 мужчин и 3 женщины в возрасте от 30 до 56 лет $(\mathrm{M}=44.61, \sigma=8.28)$;

3) 14 режиссеров театра и кино, 10 мужчин и 4 женщины в возрасте от 25 до 68 лет $(\mathrm{M}=40.31, \sigma=12.78)$.

Контрольная группа: 593 студента факультета психологии МГУ имени М.В. Ломоносова, 126 мужчин и 467 женщин в возрасте от 18 до 26 лет $(\mathrm{M}=19.41, \sigma=1.28)$.

Студенты-психологи тестировались небольшими группами, представители творческих профессий - в индивидуальном порядке.

Креативность диагностировалась с помощью методики Креативные заголовки (Sternberg, The Rainbow

\footnotetext{
${ }^{1}$ Здесь и далее с прописной буквы обозначены латентные переменные, как это принято при использовании метода структурного моделирования.
} 
Project Collaborators, 2006). В модифицированной версии методики (Павлова, Корнилова, 2012) испытуемому предлагалось придумать заголовки к шести карикатурам, которые затем оценивались тремя экспертам в соответствии с разработанной авторами системой критериев (для построения индексов креативности использовались только три «новые» карикатуры). Перевод качественных данных в количественные осуществлялся в рамках IRT-подхода с использованием многоаспектной модели Рашта (Linacre, 1989) с помощью статистического пакета Facets (V. 3.65.0).

Измерялись показатели прямой самооценки креативности (по процедуре А. Фернхема для самооценки интеллекта - см: Chamorro-Premuzic, Furnham, 2006). В этой методике испытуемому предлагается оценить свой уровень развития креативности как способности к созданию новых идей в IQ-баллах.

Для диагностики толерантности $\kappa$ неопределенности использовался Новый опросник толерантности к неопределенности - НТН (Корнилова, 2010а), включающий в себя три шкалы: «Толерантность к неопределенности» («ТН», личностное свойство готовности принимать новизну, изменения), «Интолерантность к неопределенности» ( ИТН», самостоятельная переменная, стремление избегать неопределенных ситуаций) и «Межличностная интолерантность» («МИТН», непринятие неопределенности в межличностных отношениях).

Для диагностики интуитивного стиля использовались шкалы «Использование интуиции» («ИИ») и
«Интуитивная способность» («ИС») из Опросника РациональныйОпытный С. Эпстайна (Корнилова, Корнилов, 2013). Шкала «ИИ» диагностирует тенденции испытуемого полагаться на интуицию при принятии решений, а шкала «ИС» - представления испытуемого о своей способности к формированию точных предчувствий.

Для целей построения структурной модели также использовались следующие показатели:

- Прямая самооценка интеллекта (СОИ) - методика, в которой испытуемому предлагается оценить свой уровень развития интеллекта в IQбаллах (Корнилова, Новикова, 2011).

- Личностная готовность к риску, измеренная с помощью Опросника ЛФР-21 (Корнилова и др., 2010) и диагностирующая готовность к действиям при заведомо недостаточности ориентиров.

- обиая самоэффективность (Шварцер и др., 1996), которая диагностирует уверенность испытуемого в достаточности его усилий для достижения целей.

\section{Результаты}

В нижней левой части таблицы 1 (под диагональю) представлены результаты корреляционного анализа на выборке студентов-психологов. Согласно полученным результатам, самооценка креативности связана с «ТН» и шкалой «Интуитивная способность» (с ней же связана и «ИТН») и на уровне тенденции $(p=0.050)-$ с креативностью. Обнаружены ожидаемые связи шкал внутри опросникоB. 
Таблица 1

Матрица интеркорреляций ( $\rho$ ) переменных. Над диагональю приведены результаты состоявшихся представители творческих профессий, под диагональю результаты контрольной группы

\begin{tabular}{|l|c|c|c|c|c|c|c|}
\hline & $\mathbf{1}$ & $\mathbf{2}$ & $\mathbf{3}$ & $\mathbf{4}$ & $\mathbf{5}$ & $\mathbf{6}$ & $\mathbf{7}$ \\
\hline $\begin{array}{l}\text { 1. Самооценка } \\
\text { креативности }\end{array}$ & & $0.429^{* *}$ & -0.223 & -0.039 & 0.121 & 0.248 & $0.407^{* *}$ \\
\hline 2. Креативность & 0.185 & & -0.163 & -0.151 & 0.101 & 0.105 & 0.145 \\
\hline $\begin{array}{l}\text { 3. Толерантность к } \\
\text { неопределенности }\end{array}$ & $0.158^{*}$ & -0.005 & & 0.023 & -0.107 & $0.473^{* *}$ & $0.332^{*}$ \\
\hline $\begin{array}{l}\text { 4. Интолерантность к } \\
\text { неопределенности }\end{array}$ & -0.040 & -0.094 & $-.250^{* *}$ & & $.422^{* *}$ & 0.145 & 0.024 \\
\hline $\begin{array}{l}5 . \text { Межличностная } \\
\text { интолерантность }\end{array}$ & -0.107 & -0.070 & $-.239^{* *}$ & $.258^{* *}$ & & -0.018 & -0.082 \\
\hline $\begin{array}{l}\text { 6. Интуитивная } \\
\text { способность }\end{array}$ & $0.171^{*}$ & -0.037 & .097 & $.154^{*}$ & -0.085 & & $0.779^{* *}$ \\
\hline $\begin{array}{l}\text { 7. Использование } \\
\text { интуиции }\end{array}$ & 0.083 & -0.037 & .093 & .022 & -0.093 & $0.671^{* *}$ & \\
\hline
\end{tabular}

${ }^{*} p<0.05,{ }^{* *} p<0.01$.

В верхней правой части таблицы 1 (над диагональю) показаны корреляционные связи между изучаемыми переменными на выборке состоявшихся представителей творческих профессий: самооценка креативности связана с креативностью и шкалой «Использование интуиции», «ТН» связана с обеими шкалами Опросника Эпстайна. Показаны также связи внутри шкал опросников.

С использованием конфирматорного факторного анализа была построена структурная модель, связывающая латентные переменные Креативности, Принятие неопределенности и риска и Самооценка креативности и интеллекта (см. рисунок 1). Структурная модель была построена при помощи пакета статистической обработки EQS 6.2 for Windows, использовался метод максимального правдоподобия с поправкой на ненормальность данных (Bentler, 1995). Построение модели осуществлялось на данных студентов факультета психологии МГУ (n= 287). Показано, что модель характеризуется удовлетворительными индексами пригодности: Satorra-Bentler $\chi^{2}(17)=18.12, p=0.38$, $\mathrm{CFI}=0.982, \mathrm{RMSEA}=0.015,95 \% \mathrm{CI}$ от 0.000 до 0.057 .

Латентная переменная Креативность построена нами по экспертным оценкам трех рисуночных ситуаций; однако в интегративную модель вошли только две из них, так как включение третьей ухудшало показатели модели (оценки именно по 
Структурная модель, связывающая латентные переменные Креативности, Принятия неопределенности и Самооценки креативности и интеллекта

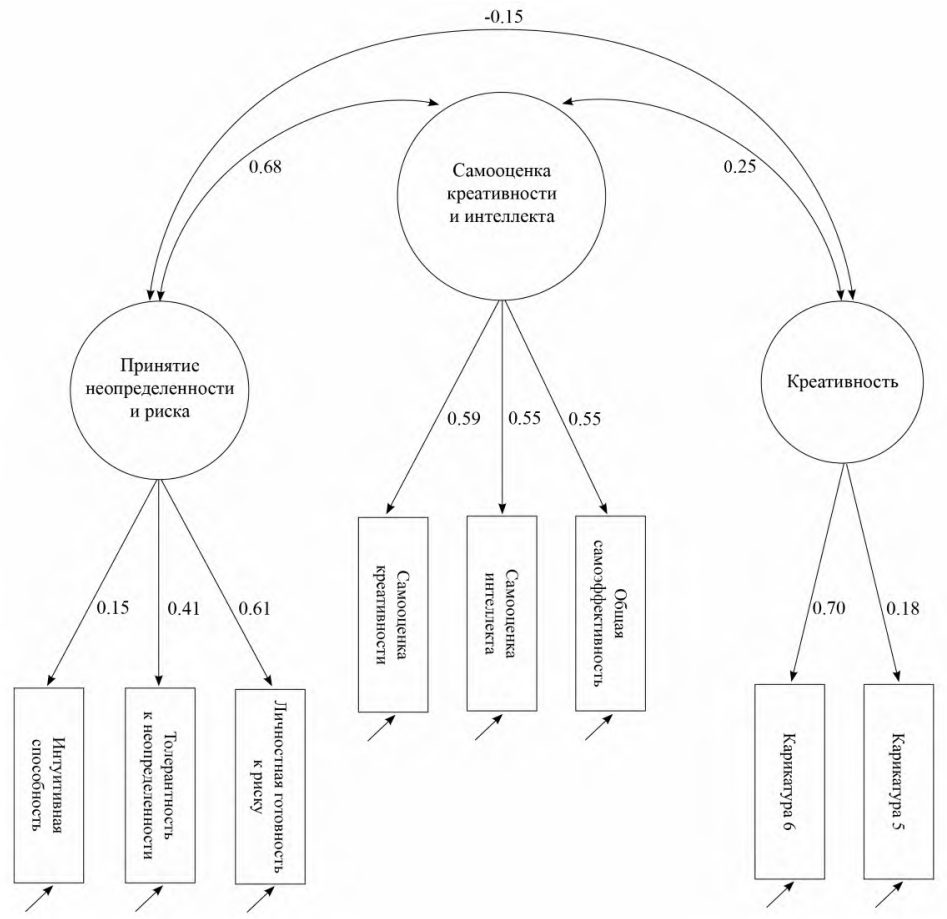

этой карикатуре характеризуются наибольшим разбросом данных). Латентная переменная Принятие неопределенности и риска включила те же измеряемые личностные переменные, что уже были показаны ранее (Корнилова и др., 2010). Самооценка интеллекта и креативности выступила предложенной нами интегративной переменной, которая манифестируется тремя измеренными: СОК, СОИ и шкалой «Самоэффективность».

\section{Обсуждение результатов}

Согласно полученным результатам, самооценка креативности у сту- дентов-психологов связана со шкалой «ТН» и (на уровне тенденции) с креативностью, измеренной с помощью методики Креативные заголовки. Таким образом, построение самооценки базируется на принятии неопределенности, заложенной в самом процессе самооценивания с неявными критериями, результаты творческой деятельности для этой выборки играют менее выраженную роль. Напротив, у состоявшихся представителей творческих профессий самооценка связана с креативностью по методике Креативные заголовки, т.е. оценка себя строится на основе объективных результатов творческой деятельности. 
В предыдущих исследованиях (Корнилова, Корнилов, 2013) была показана связь интуитивного стиля с самооценкой интеллекта (СОИ), нами продемонстрирована подобная связь с самооценкой креативности. При этом на обеих выборках не была продемонстрирована связь шкал Опросника Эпстайна с показателями креативности, что также подтверждает результаты предыдущих исследований (Там же). Данные корреляционного анализа позволяют предположить наличие связи креативности и интуитивного стиля через показатели самооценки креативности, в первую очередь в отношении состоявшихся представителей творческих профессий.

С использованием конфирматорного факторного анализа нами была построена структурная модель, связываюшая латентные переменные Принятия неопределенности и риска, Креативности и Самооценки креативности и интеллекта (см. рисунок 1). Полученные связи латентных переменных соответствуют данным зарубежных исследователей о корреляциях между измеряемыми переменными (Furnham et al., 2011; Hughes et al., 2013; и др.), а также отечественных - о связях между латентными переменными (Корнилова, Новикова, 2011), однако нами они впервые продемонстрированы в структурной модели, в которую входит Креативность.

Неожиданной выступила отрицательная связь латентных переменных Креативности и Принятия неопределенности и риска. Однако такой результат соответствует дан- ным о том, что толерантность к неопределенности не обязательно сопутствует креативности, а интолерантность к неопределенности мешает проявлению креативного потенциала (Корнилова, 2010б).

В исследовании Т.В. Корниловой и М.А. Новиковой (Корнилова, Новикова, 2011) Интегративная Я્ концепция выступила в качестве опосредующей связи СОИ и Интеллекта. Мы также склонны рассматривать латентную переменную Самооценки креативности и интеллекта в качестве связующего звена между Креативностью и Принятием неопределенности и риска. В отличие от самооценки интеллекта, которая связана с показателями психометрического интеллекта только через промежуточное звено принятия неопределенности, интегральная Самооценка находится в связях как с процессами принятия неопределенности и риска, так и с достижениями в творческой деятельности.

Ранее нами было показано, что шкалы имплицитных теорий креативности (более глубинные образования, представленные, однако, на уровне самосознания в самоотчетах) выступают предикторами прямой самооценки креативности у представителей творческих профессий (Павлова, 2014). Интегративная самооценка креативности и интеллекта (как латентная переменная) скорее представлена на более высоком уровне самосознания личности. Согласно полученным нами результатам, эта латентная переменная в большей степени связана с позитивным принятием неопределенности и риска. 


\section{Выводы}

1. Верифицирована структурная модель связей между латентными переменными Креативности, интегральной Самооценки креативности и интеллекта и Принятия неопределенности и риска.
2. Самооценка креативности и интеллекта базируется как на процессах принятия неопределенности, так и на достижениях в творческой деятельности.

\section{Литература}

Корнилова, Т. В. (2010а). Новый опросник толерантности к неопределенности. Психологический журиал, 1, 74-86.

Корнилова, Т. В. (2010б). Толерантность к неопределенности и интеллект как предпосылки креативности. Вопросы психологии, 5, 3-12.

Корнилова, Т. В. (2013). Психология неопределенности: Единство интеллектуально-личностной регуляции решений и выборов. Психологиеский журнал, 34(3), 89-100.

Корнилова, Т. В. (2016). Интеллектуально-лииностньй потенииал человека в условиях неопределенности и риска. СПб.: Нестор-История.

Корнилова, Т. В., Корнилов, С. А. (2013). Интуиция, интеллект и личностные свойства (результаты апробации шкал опросника С. Эпстайна). Психологические исследования, 6(28), 5. Режим доступа: http://psystudy.ru/index.php/num/2013v6n28/804-corniliva28.html

Корнилова, Т. В., Новикова, М. А. (2011). Самооценка интеллекта в структуре интеллектуальноличностного потенциала человека. Психологичский журнал, 32(2), 25-35.

Корнилова, Т. В., Чумакова, М. А., Корнилов, С. А., Новикова, М. А. (2010). Психология неопределениости: единство интеллектуально-линиостного потенииала человека. М.: Смысл.

Любарт, Т., Муширу, К., Торджман, С., Зенасни, Ф. (2009). Психология креативности. М.: Когито-центр.

Павлова, Е. М. (2014). Имплицитные теории и самооценка креативности в структуре самосознания личности. Психология. Журнал высией иколь экономики, 11(4), 75-95.

Павлова, Е. М., Корнилова, Т. В. (2012). Креативность и толерантность к неопределенности как предикторы актуализации эмоционального интеллекта в личностном выборе. Психологиеский журнал, 33(5), 39-49.

Шварцер, Р., Ерусалем, М., Ромек, В. (1996). Русская версия шкалы общей самоэффективности Р. Шварцера и М. Ерусалема. Нностранная психология, 7, 71-77.

Ссылки на зарубежные источники см. в разделе References после англоязыиного блока.

Павлова Елизавета Михайловна - инженер, кафедра психологии образования и педагогики, факультет психологии, Московский государственный университет имени М.В. Ломоносова, кандидат психологических наук.

Сфера научных интересов: креативность, творчество, принятие неопределенности, эмоциональный интеллект, интеллектуально-личностный потенциал.

Контакты: pavlova.lisa@gmail.com 


\title{
Model of Connections between Self-Esteem of Creativity and Intelligence, Tolerance of Uncertainty and Creativity.
}

\author{
E.M. Pavlova ${ }^{a}$ \\ ${ }^{a}$ Lomonosov Moscow State University, GSP-1, Leninskie Gory, Moscow, 119991, Russian Federation
}

\begin{abstract}
Relation between self-esteem and creativity (as a cognitive ability) highlights the regulative function of the self-awareness. Self-esteems of different kinds and different generality function in interaction with other components of intellectual and personal potential of a person, and they take leading role in psychological regulation of person's productive activity. Tolerance for uncertainty and intuition are such components, and they are connected to the productive choice and other types of novelties. In this paper we describe a study of creativity (as a result of subject's creative behavior assessed by experts), its self-assessment, intuitive style, and tolerance for uncertainty among creative professionals (writers, composers, and directors, $n=53$ ) and control group of psychology students $(n=593)$. With correlation analysis, we show that psychologists base their self-esteem on acceptance of uncertainty, whereas creative professionals orient toward the objective results of their creative activity. Using the confirmatory factor analysis we verify structural model of Creativity, integral Self-esteem of creativity and intelligence and Acceptance of uncertainty and risk. The positive connection of integral Self-esteem with Creativity and Acceptance of uncertainty and risk was shown as well as the negative connection between Creativity and Acceptance of uncertainty and risk. According to the results, unlike self-esteemed intelligence, integral self-esteem is connected both to acceptance of uncertainty and success in creative activity.
\end{abstract}

Keywords: creativity, self-assessed creativity, tolerance for uncertainty, risk-readiness, intelligence, intuition, creative professionals.

\section{References}

Bentler, P. M. (1995). EQS structural equations program manual. Encino, CA: Multivariate Software.

Chamorro-Premuzic, T., \& Furnham A. (2006). Self-assessed intelligence and academic performance. Educational Psychology: An International Joumal of Experimental Educational Psychology, 26(6), 769-779.

Furnham, A., Batey, M., Booth, T. W., Patel, V., \& Lozinskaya, D. (2011). Individual difference predictors of creativity in Art and Science students. Thinking Skills and Creativity, 6(2), 114-121.

Hughes, D. J., Furnham, A., \& Batey, M. (2013). The structure and personality predictors of self-rated creativity. Thinking Skills and Creativity, 9, 76-84.

Ivcevic, Z., \& Mayer, J. D. (2009). Mapping dimensions of creativity in the life-space. Creativity Research Journal, 21(2-3), 152-165.

Jacobs, K. E., Szer, D., \& Roodenburg, J. (2012). The moderating effect of personality on the accuracy of self-estimates of intelligence. Personality and Individual Differences, 52(6), 744-749. 
Kaufman, J. C., \& Baer, J. (2005). The amusement park theory of creativity. In J. C. Kaufman \& J. Baer (Eds.), Creativity across domains: Faces of the muse (pp. 321-328). Mahwah, NJ: Lawrence Erlbaum Associates.

Kaufman, J. C., Beghetto, R. A., Baer, J., \& Ivcevic, Z. (2010). Creativity polymathy: What Benjamin Franklin can teach your kindergartener. Leaming and Individual Differences, 20(4), 380-387.

Kornilova, T. V. (2010a). Noviy oprosnik tolerantnosti k neopredelennosti [The New Questionnaire of Tolerance for Uncertainty]. Psikhologicheskiy Zhumal, 1, 74-86.

Kornilova, T. V. (2010b). Tolerantnost k neopredelennosti i intellekt kak predposylki kreativnosti [Tolerance for uncertainty and intelligence as prerequisite of creativity]. Voprosi Psikhologii, 5, 3-12.

Kornilova, T. V. (2013). Psychologiya neopredelennosti: edinstvo intellektual'no-litchnostnoi regulazii resheniy i vyborov [The Psychology of Uncertainty: unity of intellectual and personal regulation of decision and choices]. Psikhologicheskiy Zhumal, 34(3), 89-100.

Kornilova, T. V. (2016). Intellektualno-lichnostnyj potencial cheloveka v uslovijah neopredelennosti $i$ riska [Intellectual and personal potential of a person in conditions of uncertainty and risk]. Saint Petersburg: Nestor-Istoria.

Kornilova, T. V., \& Kornilov, S. A. (2013). Intuiciya, intellect i lichnostnie svoistva (rezultati aprobacii oprosnika S. Epstaina) [Intuition, intelligence, and personality traits (the results of trying and testing Rational Versus Experiential Inventory by S.Epstein et al.)]. Psikhologicheskie Issledovaniya, 3(11), 5. Retrieved from http://psystudy.ru/index.php/num/2013v6n28/804-corniliva28.html

Kornilova, T. V., \& Novikova, M. A. (2011). Samoocenka intellekta v strukture intellektualno-lichnostnogo potenciala cheloveka [Self-esteem of the intelligence in the structure of the person's intellectual-personal potential]. Psikhologicheskiy Zhumal, 32(2), 25-35.

Kornilova, T. V., Chumakova, M. A., Kornilov, S. A., \& Novikova, M. A. (2010). Psikhologiya neopredelennosti:Edinstvo intellektualno-lichnostnogo potentsiala cheloveka [The psychology of uncertainty: The unity of the intellectual and personality potential of a man]. Moscow: Smysl.

Linacre, J. (1989). Many-facet Rasch Measurement. Chicago: MESA Press.

Lubart, T., Mushiru, K., Torgman, S., \& Zemasni, F. (2009). Psychology of creativity. Moscow: Cogito-centr.

Pavlova, E. M., \& Kornilova, T. V. (2012). Creativity and tolerance to uncertainty as predictors for emotional intelligence actualization in personal choice. Psikhologicheskii Zhurnal, 33(5), 39-49.

Pavlova, E.M. (2014). Implicit theories and self-evaluation of creativity in the structure of personal self-conception. Psychology. Journal of the Higher School of Economics, 11(4), 75-95. (in Russian)

Reiter-Palmon, R., Morral, E., Kaufman, J. C., \& Santo, J. B. (2012). Evaluation of self-perceptions of creativity: Is it a useful criterion. Creativity Research Joumal, 24(2-3), 107-114.

Schwarzer, R., Jerusalem, M., \& Romek, V. (1996). Russkaja versija shkaly obshhej samojeffektivnosti R. Shvarcera i M. Erusalema [Russian version of the R. Schwarzer and M. Erusalem's scale of general self-efficacy]. Inostrannaja Psihologija, 7, 71-77.

Sternberg, R. J., \& The Rainbow Project Collaborators. (2006). The Rainbow Project. Enchancing the SAT through assessments of analytical, practical, and creative skills. Intelligence, 34(4), 321-350.

Zenasni, F., Besancon, M., \& Lubart, T. I. (2008). Creativity and tolerance of ambiguity: An empirical study. Jourmal of Creative Behavior, 42(1), 61-73.

Elizaveta M. Pavlova - engineer, Department of Educational and Pedagogical Psychology, Department of Psychology, Lomonosov Moscow State University, Ph.D.

Reseach area: creativity, creation, tolerance of uncertainty, emotional intelligence, intellectual and personal potential.

Email: pavlova.lisa@gmail.com 